\title{
Institutes of public health and medical schools: grasping defeat from the jaws of victory?
}

"We recommend that the relevant training institutions and professional bodies should discuss how best to achieve multidisciplinary awareness and collaboration in the training of public health practitioners including the possibility of establishing a school or schools of public health. In addition, there may also be merit at regional level in considering the school of public health concept in other locations bringing together existing departments. .."1 (E D Acheson)

"In 1916 the Rockfeller Foundation determined that insufficient attention was being paid to environmental and social factors in disease. The population perspective was neglected domestically and abroad, appropriately trained health officers and other public health personnel were needed urgently everywhere. The Foundation's officer decided that the solution was to establish schools of public health apart from schools of medicine. Henceforth the latter's mission was the care of individual patients and investigations of disease processes. The former were now to be responsible for studying the determinants of health and disease in populations; they were to formulate strategies requiring collective action to improve the public's health. Medical schools lost interest in epidemiology, the social sciences, and quantitative methods. . 1

The narrowed mission of the medical school resulted in gradual abrogation of the social contract between the medical establishmentespecially the academic component-and the public from which it derives its status. Medicine lost touch with the full array of the population's health problems and needs, and many in the public health arena lost touch with developments in the mainstream of biomedical and clinical advances. Public health could have profited through closer association and of greater importance, influenced medicine's priorities and values. Both medicine and public health were losers, to say nothing of the populations served."2 (Kerr L White)

"For most of the twentieth century the medical school's endeavour has embraced two dominant preoccupations. The first is clinically based and focuses on the core of individual patients, one at a time. The second is laboratory based and concerned with cellular and molecular disease processes. Biomedical research and technological development are essential for teaching and for providing graduates with a set of indispensable competencies to meet individual patient needs for medical care. At the end of this century this component has a high profile; is demonstrably productive, widely understood and with some exceptions, well-resourced. These successes however have been accompanied by serious educational imbalances. Among these are the domination of narrowly defined biomedical aspects of disease in individual patients to the exclusion of other equally important considerations bearing on the patients care and well-being. A third domain of the medical school's endeavour uses knowledge and experiences derived from population-based (public health) approaches. These are essential for providing graduates with another set of competencies to facilitate understanding other vital determinants that affect the natural history and management of each patient's illness as well as the disease process". ${ }^{3}$ (Kerr White and Julia E Connelly)

"There is clearly a need for a greater concern with public health matters in medical schools. Yet one has to question whether the national trend towards creating, within universities, Schools of Public Health that are separate from the medical schools has not inhibited the development of educational facilities for medical students. For too many, public health has been a postgraduate activity..." (Sir Christopher Booth)

"A real tragedy for the United States system of medical education in recent decades has been the separation and isolation of schools of medicine and schools of public health-within the same university. One strong recommendation I would offer is that schools of medicine and schools of public health co-operate fully to address the health needs of the community". (Harry S Jonas)

"The Reform of medical education requires a redefinition of the medical school. Instead of a place, a campus, a group of buildings it should be an organisation that is immanent in the whole health care system. It should be as much a presence in the rural hospital, the nursing home, the public unit, and the inner city or rural practice, as it is in the tertiary care hospital and the laboratory. It follows also that those who teach should represent the whole profession in some proportion to their numbers, as well as our sister health professions from whom we have so much to learn. . . If the medical school is to be immanent in the health care system, it follows that the school should not own any one part of it, or provide any service directly. The school can then provide learning environments by entering into agreement with institutions of many different kinds." (Ian R McWhinney)

"My personal view is that the undergraduate curriculum should be comprehensive, even at the expense of fine detail, for the essential function is to give the student some comprehension of what is involved in the many modes of medical care, without equipping (him) for the immediate independent practice of any one of them. It follows that no major theme of health care should be omitted from it, and in particular that curriculum that leaves the students unaware of the population discussion is a fatally planned curriculum. But to me the antitheses between the population dimension and the individual dimension is incomplete, and the ideal curriculum should recognise that population problems are aggregations of individual problems. Should the graduate ultimately choose a career in public health or epidemiology (he) should still feel confident in facing health problems in patients who come (his) way. If their curriculum has prepared them also for this, they will enjoy a success that (in the words of Donald Acheson) will depend 'on the degree to which their work meets their professional aspirations and is seen to leaven medicine from within rather than to belabour it from without'." (Sir Douglas Black)

The reason for starting off this paper with a series of quotes is that having offered to write something for the forum I rapidly realised that a great deal of very good quality thinking on public health, public health schools, and medical schools has recently been taking place and much of it has been brought together under the influence of Kerr White in two books published by Springer-Verlag. ${ }^{2} 3$ 
For me much of the argument as summarised in the above quotations makes immediate sense and poses an exciting and timely challenge at a point of such radical change in our thinking about health systems and services and as we contemplate radical change in the organisation of our domestic health services, of the medical undergraduate curriculum and of biomedical, health services, and health-related research. The point of my subtitle is to raise the question - at the very time that a reappraisal of the relative contributions of the clinical, the biomedical, and the population perspectives is underway are we not institutionalising Kerr White's schism between epidemiology, medicine, and public health by the rush to institutional development? Since the Acheson report was published in $1988^{1}$ there has been a veritable epidemic of new schools and institutes of public health, both at home where many are being set up separate from medical schools or universities, and increasingly also abroad. McWhinney's plea ${ }^{6}$ for what is essentially a sort of networked medical school seems to be much more in keeping with the spirit of the times and with current organisational forms which seek to gear themselves up to be responsive to constant change and which link together all the key players.

The argument is quite straightforward. Kerr White and others have argued that in the evolution of scientific and social capabilities for responding to threats to health, our efforts have become fragmented and we have lost our way. ${ }^{2}$ This has led to a schism which separates especially the population based public health approach from the heart of medical thinking but which also to a certain extent has led to an inbalance between the laboratory based and clinical endeavours. As a consequence medicine and medical schools have become distanced from their roots in the communities which they should serve and there has been a breakdown of the social contracts with those communities. In Europe and North America three distinct phases of activity in relation to public health and organised health care can be identified in the last 150 years. ${ }^{8}$

The first period between 1840 and 1900 was one of sanitary reform. The rapid urbanisation which took place in Europe and North America during the 18th century created miserable living conditions for the urban poor. Eventually local governments, responding in part to pressure from groups such as the Health of Towns Association in England, appointed city medical officers to enforce national and local legislation aimed at tackling environmental squalor, along with the problems of poor food, water, and personal hygiene. The vigorous application of the "sanitary idea" undoubtedly had a major impact within a comparatively short time.

Advances in bacteriology and the development of immunisation brought with them powerful personal prevention opportunities. This second phase can be dated from 1880 to approximately 1930 . Action to improve the health of populations changed somewhat and local councils began to develop child and family health clinics, both in schools and in the community, with birth control services increasingly becoming available to many sections of the community. In some countries other preventive services were also developed, such as free milk and meals in schools, and this helped to compensate for the endemic malnutrition of the urban poor.

McKeown has argued that, with the exception of vaccination against smallpox, it is unlikely that immunisation or therapy had a significant effect on mortality from infectious disease before the 20th century. In particular, most of the reduction in mortality from tuberculosis, bronchitis, pneumonia and influenza, whooping cough, and food and water-borne disease had already occurred before effective immunisation or treatment were available. ${ }^{9}$ It was only in the 1920 s and 1930 s that scientific medical treatments began to have an impact on mortality. McKeown's view is that environmental measures (sanitation, improved housing, food hygiene) and behaviour change (birth control resulting in fewer, more spaced out births) made the major contribution to improved family health.
The preventive phase was gradually eclipsed by the therapeutic era (1930-74) with the advent of insulin, the sulphonamide antimicrobials, and, later, the explosion of therapeutic possibilities. The beginning of this period coincided with the apparent disappearance of the major infectious diseases on the one hand, and the increasing involvement of governments in the provision of health and social services on the other. Many people seem to have equated the one with the other, and until recently the popular view appears to have been that improvements in health have come about as a direct result of advances in medical care. Historically, the therapeutic phase marked a weakening of public health departments and of the role of general medical practitioners and a shift of power and resources to a hospital-based services and the ascendancy of biomedical research.

The origins of the fourth phase, the "new public health" movement, can be traced to growing awareness of the limitations of therapy promoted by McKeown and others such as Ivan Illich in his book Medical Nemesis, first published in $1975 .^{10}$ In the late 1960 s and early 1970 s there had been growing concern at the voracious financial appetite of medical care systems throughout the world, and the crisis of costs was brought to a head by the international oil price crisis which followed the Arab-Israeli war of 1973.

In 1974 Marc Lalonde published $A$ New Perspective on the Health of Canadians, focusing attention of the fact that a great deal of premature death and disability was avoidable. ${ }^{11}$ It is arguable that it was this report which began to set a new agenda for preventive medicine and signalled the turning point in efforts to rediscover public health in developed countries. From Lalonde's and similar reports from around the world a similar list of medical priorities emerges: heart disease, stroke, cancer, accidents, alcohol, drugs, suicide (mental health), and AIDS.

The World Health Organisation's Global Strategy of Health for All by the Year $2000^{12}$ with its emphasis on reducing inequalities in health, increasing public participation, the recognition of the part to be played in health development by sectors other than the narrowly biomedical and the emphasis on primary health care; the British government's health service reforms which signal a significant reorientation from a hospitalbased system to one which emphasises prevention, primary, and community care and most recently The Health of the Nation strategy ${ }^{13}$ very much reflect this set of priorities.

In turning its attention to settings (healthy cities, schools, workplaces, homes, hospitals, prisons and environments) The Health of the Nation ${ }^{13}$ underlines the relevance of the environment to health. In fact what has been emerging in recent years as the new public health is an approach which takes account of the massive demographic change which has been taking place and the change from infectious and acute disease to noninfectious, chronic disease. Its protagonists have argued for a more appropriate balance between environmental changes and personal preventive measures together with appropriate therapeutic interventions. This points towards a fundamental reorientation of medical care away from hospital care towards health promotion, preventive medicine, primary and community care, something which is implicit both in the Tomlinson report and in the similar reviews which are taking place around the country. ${ }^{14}$ All of this has profound implications for research and teaching some of which are already being addressed by the Peckham research committee and others by the General Medical Council's curriculum review. However, while these various developments appear to represent a convergence of thinking about health service organisation, teaching, and research which might be expected to lead to a more coherent, appropriate, and effective approach to the nation's health, the potential fragmentation which is represented by the development of new separate institutions whether for research or teaching is in some danger of being overlooked. 
It seems to me as a public health doctor that one of the main problems we have is a conceptual one about the mission of medicine and the nature of public health-issues which are recurrently addressed in Kerr White's two books. ${ }^{2} 3$

The questions which emerge for me in reading Healing the Schism ${ }^{2}$ are as follows:

What is the task (vision and mission) of medicine?

How has it changed?

What is now needed?

Once we know what the function is, how can we develop appropriate structures to support its effective prosecution? (do we need new ones or can we adapt the old?)

What hierarchies of organisational division make sense in relation to functions such as research, teaching, and service at a regional, national, and international level? What is the appropriateness of specialised topic based divisions and institutions?

In the Acheson enquiry report ${ }^{1}$ public health was defined as "the science and art of preventing disease, prolonging life and promoting health through the organised efforts of society". This is a broad and encompassing definition which if adopted would tend to imply that the medical school itself together with many present and potential future linkages should be seen as a school of public health. This suggestion is not a megalomaniacal bid by a public health practitioner to control the world but rather a perspective in which public health instead of being a subset of medicine would be seen as the whole enterprise and as a result the skills needed to take a population approach and which include those at the heart of the practice of public health medicine (such as epidemiology, statistics, social and behavioural science) would be expected to pervade the curriculum in the same way that health education should pervade the primary and high school curriculum. In some specialist areas such as psychiatry, geriatrics, and paediatrics and in some departments of primary care this has long been the case. The relevance of, for example, epidemiology to every aspect of medicine is clear from the chapter headings of Professor Jerry Morris's seminal book, The Uses of Epidemiology: ${ }^{15}$

Historical study;

Community diagnosis: community health;

The working of health services;

Individual chances and risks;

Identification of syndromes;

Completing the clinical picture;

In search of causes.

This is not to argue that the role of the medical schools is to turn out only public health doctors but that the fundamental orientation of the school should be grounded in a commitment of its local population taken as a group and an understanding of that population's health; such a grounding should be seen as at least as important as that in the basic biological sciences. A minority of graduates (whether medical or non-medical) are required who will specialise in the population perspective. For about $50 \%$ who will work in primary care either as doctors or other health workers with a clear responsibility for a defined locality based population, an understanding of epidemiology and the public health sciences should go well beyond basic literacy while for those who work in the secondary or tertiary care sectors there is a range of appropriate levels of competence from basic literacy in the very technical to highly developed among clinical directors.

This perspective leads to a number of other conclusions on such issues as the scope for medical schools to train health workers other than doctors, the extent to which schools collaborate and communicate with other local institutions and community organisations, and the extent to which their "agenda" is congruent with that of the health and local authorities while protecting the tradition of independence of thought.

In White and Connolly's book, ${ }^{2}$ The Medical School's Mission and the Population's Health, which represents the edited proceedings of a conference, three sets of objectives are identified:

"1 Individual patient-physician level: All graduates should understand the natural history of each patient's disease, possible methods of prevention and health promotion, as well as the management of the individual's illness in relationship to psychological, social, occupational, and environmental factors in its genesis, and in the contexts of treatment and management, and the community resources to be invoked.

For example, graduates should know the relative importance of conditions in both small populations ( 1000 to 3000 persons) served by primary care generalists (general practitioners, family physicians etc) and in large populations $(100,000$ to $1,000,000$ or more), and the nation. These are frequently expressed in measures based, for example, on age, sex, and occupational prevalence, functional states, and extent of unmet need. Graduates should also know the indications, potential risks, benefits and costs of diagnostic and therapeutic interventions. Faculty with clinical responsibilities should encourage understanding and application of this knowledge in concert with colleagues from the population-based disciplines.

2 Institutional level; All medical schools and their affiliated institutions should assume responsibility for addressing the health needs of a general population. Fulfilling these societal obligations is best accomplished when each medical school and its affiliated institutions assumes responsibility for an explicit catchment area or defined population. These can be determined by geography or through enrolment in group practices, clinics, health maintenance organisations, and the like.

Where two or more medical schools exist in close proximity, especially in densely populated metropolitan areas without any formal regionalisation scheme, responsibility for potential populations will need to be negotiated. Those schools whose faculties believe they have national and global missions should also promote active dissemination of the population perspective; they too will need to define a population for whose health status they recognise responsibility.

3 To teach and investigate many aspects of population medicine, especially such components as primary medical care, disease prevention, and health promotion, requires each medical school to establish contractual or other agreements with a variety of communitybased health institutions, ambulatory clinics, and practice-based sites. Appropriate teachers in such settings will require faculty appointments. These educational consortia and networks should enjoy administrative, financial and material resources on a par with those accorded tertiary care services."

The conference went on to make five recommendations to medical schools on goals and objectives, faculty development, education, educational resources, and health intelligence.

"Goals and objectives: Each medical school should develop and publicise a mission statement of goals and objectives that defines its commitment to both individuals and populations. This statement should reflect clear recognition and understanding of the nature and intent of the contract that exists with the population it serves, however defined. The statement should cover undergraduate, and where feasible postgraduate, education, research and service. Arrangements should be defined for implementing these goals and objectives with representatives of the population to be served. The statement should include strategies for evaluating progress towards the institutions's goals and objectives using population-based and individual outcomes.

Faculty development: Each medical school should establish methods to ensure that each faculty member understands the distribution of health problems in the population served.

Education: Each medical school should establish methods to ensure that each graduate has acquired knowledge, skills, and attitudes that reflect appropriate applications of individual patient-physician, biomedical, and population-based perspectives.

Educational resources: Each medical school should assemble an adequate breadth of resources (faculty and facilities) to ensure that all students have a balanced experience with the full range of health problems in the population served, and have opportunites to work with other health professionals and agencies.

Health intelligence: Each medical school should establish a unit or links with an organisation capable of transforming raw "data" bearing on health and health services into usable "information." In turn this "information" needs to be interpreted, in social, political, and other contexts, as "intelligence" to guide the faculty and Dean in establishing institutional priorities for education, research and service. The unit should have strong ties to clinical departments, and to governmental and other community agencies, including health departments." 
Recent experience of establishing such an intelligence unit, the Public Health Observatory in Liverpool, in close conjunction with the local health authorities suggests that this may indeed be a valuable way of bridging the gap between academic research and relevance to the community and to public services.

The conference concluded that implementation of these recommendations is most likely to be accelerated through the mechanisms of institutional accreditation, examinations, certification, and especially through the process of licensure, preferably nationally on completion of all postgraduate (residency, registrar) training. Some countries may wish to consider national, state, or provincial legislation to ensure effective implementation of these or similar plans that are responsive to the public's and the profession's mounting dissatisfaction. Early introduction of these recommendations, suitably modified for each country into academic, organisational, professional, and governmental settings, accompanied by their prompt discussion can result in their adoption.

I believe together with Kerr White and others that if adopted these objectives and recommendations would be of major assistance in refocusing our endeavour, putting us back in contact with our communities and becoming explicitly a resource for them.

The concept of the medical school as a "school of health" is not a new one. Andrija Stampar worked long and hard to promote such a concept in Zagreb before and after the Second World War. In fact he was following 150 years later in the footsteps of Michel Auguste Thouret of France who became dean of what was originally called the Ecole de Santé but was renamed the Ecole de Medicine in $1796 .^{2}$

JOHN ASHTON

Member of the Editorial Committee

Department of Public Health, University of Liverpool, PO Box 147, Liverpool L69 3BX.

1 Committee of Enquiry into the Future Development of the Public Health Function. Public health in England. London: HMSO, 1988. (Cmnd 289.) Function. Public heah

2 White KL Healing the schism, epidemiology, medicine and the public's health. New York: Springer Verlag, 1991

3 White KL, Connelly JE. In: The medical school's mission and the population's health. New York: Springer Verlag, 1992.

4 Booth C In: White KL, Connelly JE eds. The medical school's mission and the population's health. New York: Springer Verlag, 1992.

5 Jones HS In: White KL, Connelly JE eds. The medical school's mission and the population's health. New York: Springer Verlag, 1992.

6 McWhinney IR In: White KL, Connelly JE eds. The medical school's mission and the population's health. New York: Springer Verlag, 1992.

7 Black D In: White KL, Connelly JE eds. The medical school's mission and the population's health. New York: Springer Verlag, 1992.

8 Ashton J, Seymour H The new public health. Milton Keynes: Open University Press, 1988.

9 McKeown T The role of medicine - dream, mirage or nemesis. London: Nuffield Provincial Hospitals Trust, 1976.

10 Illich I. Medical nemesis. London: Marion Boyars, 1975

11 Lalonde M. A new perspective on the health of Canadians. Minister of Supply and Services, 1974

12 World Health Organisation Global strategy for health for all by the year 2000. Geneva: WHO, 1981 .

13 Department of Health. The health of the nation. London: HMSO, 1992.

14 Report of the Inquiry into London's Health Services, Medical Education and Research. London: HMSO, 1992 (Tomlinson report.)

15 Morris JN. The uses of epidemiology. 3rd ed. Edinburgh: Churchill Livingstone, 1975. 